\title{
Glucose transport in human peripheral blood lymphocytes influenced by type 2 diabetes mellitus
}

\author{
Paweł Piątkiewicz, Anna Czech and Jan Tatoń \\ Chair and Department of Internal Medicine and Diabetology, Medical University of Warsaw, Warsaw, Poland
}

Received: 2006.06.01, Accepted: 2006.12.28, Published online first: 2007.03.20

\begin{abstract}
Introduction: The objective of this study was to evaluate glucose transport into lymphocytes in healthy subjects and patients with type 2 diabetes mellitus (DM) treated either with diet only or with insulin and to propose peripheral blood lymphocytes as a convenient model for cellular glucose transport studies.

Materials and Methods: Sixty subjects with type 2 DM, 30 treated with diet only and 30 with insulin, were investigated. Thirty healthy subjects matched for age, weight, and sex served as a control group. Deoxy-D-glucose, $2-\left[{ }^{3} \mathrm{H}(\mathrm{G})\right]$ transport was studied in isolated peripheral blood lymphocytes. Expression of glucose transporters was ascertained by immunocytochemical identification and by Western blotting.

Results: In lymphocytes from the control group, deoxy-D-glucose uptake increased gradually with the duration of the experiment. In diabetics treated with insulin, the maximal increase in deoxy-D-glucose uptake was observed after 30 min of the investigation, followed by a plateau phase. In diabetics treated with diet, deoxy-D-glucose uptake increased slowly during the first $30 \mathrm{~min}$. The presence of GLUT1 and GLUT3 in lymphocytes was confirmed in this study.

Conclusions: Glucose transport into lymphocytes is altered in type 2 DM. In lymphocytes from diabetics, the dynamics of deoxy-D-glucose uptake significantly differed from that in healthy subjects. There was also a significant difference between the diabetic groups, representing different modes of therapy and stages of the disease. Glucose transport into lymphocytes is apparently influenced by DM as well as by the mode of therapy. We suggest that peripheral blood lymphocytes may become a promising model for studies on glucose transport in diabetes.
\end{abstract}

Key words: type 2 diabetes mellitus, glucose transport, lymphocytes, GLUT.

Corresponding author: Paweł Piątkiewicz, Chair and Department of Internal Medicine and Diabetology, Medical University of Warsaw, Brodnowski Hospital, Kondratowicza 8, 03-242 Warsaw, Poland, tel.: +48 22 326-58-17, fax: +48 22 326-58-17, e-mail: piatkiewicz@op.pl

\section{INTRODUCTION}

Glucose transport defects in diabetes mellitus (DM) lead to the impairment of the rate of glucose utilization by peripheral tissues. The first step of this complex process is cellular glucose transport, the properties of which in peripheral blood lymphocytes of diabetic patients are not known and information on glucose transporters in these cells is scarce and inconsistent. Moreover, inadequate metabolism of glucose in these cells is the reason for the significant impairment of their function. So far, a number of studies have focused on glucose transport under various metabolic conditions. These studies, however, concerned almost exclusively the classically defined insulin-dependent tissues, i.e. muscle and adipose tissue $[2,13,20]$. There are also data available on glucose transport into pancreatic islet B cells $[15,16]$.
The first stage of glucose metabolism is its entry into cells by means of facilitated diffusion in the direction of a glucose concentration gradient. The glucose transport facilitators are proteins of the GLUT family. These are widely distributed proteins present in the plasma membranes of almost all cells. In human cells and tissues there are several isoforms of these transporters: GLUT1 to 12 and HMIT1, encoded by distinct genes of the $S L C 2 A$ family (a HUGO Gene Nomenclature Committee approved symbol) [17, 42]. The expression of particular genes of the $S L C 2 A$ family, including the newest member of the GLUT family, GLUT14 [43], is specific to tissues and cells [4, 10, 23, $25,32,33,36,38]$. Early studies on glucose transport into lymphocytes suggested the presence of a system of facilitated diffusion in these cells [31]. Several studies revealed that GLUTl and GLUT3 are present as glu- 
cose transporter proteins in lymphocytes [7, 11, 23]. Pathological changes in serum glucose concentration influence $S L C 2 A$ gene expression, glucose uptake, and glucose metabolism in lymphocytes [26]. Sustained hypoglycemia effects $S L C 2 A$ gene expression of human blood leukocytes, especially in granulocytes and monocytes. In granulocytes the level of GLUT4 increases by $73 \%$, whereas a reduction in GLUT1 and a rise in GLUT3 is observed. On the other hand, the majority of the lymphocyte population was found to be negative for these carriers [21].

Clinical observations and laboratory findings suggest that lymphocytes may function abnormally in DM [5, 28, $37,40]$. An increased susceptibility to infections is a well-known complication of a poorly controlled diabetic state $[18,28,39,41]$. In diabetic patients, infections take a more severe course and complications occur more often. Studies have shown that diabetes is a pathological state that influences immunity. Available publications concern altered properties of leukocytes, chemotaxis, adherence, and phagocytosis that are crucial elements in immune response $[9,12,40]$. Nonetheless, scientific evidence in this field of study is not abundant and relates mainly to polymorphonuclear leukocytes. There are some data on lymphocyte function in animal studies. In alloxan-induced diabetic rats and in obese rats with impaired glucose tolerance, decreased mitogen response of lymphocytes has been observed [27, 29].

Glucose is the most important energy source for cells with high energy consumption. This is the case for lymphocytes, which must react rapidly in response to pathogens. Altered glucose metabolism was shown to be responsible for low lymphocyte proliferation in response to mitogen [29]. Glucose transport seems to be a crucial step in this process. Its pathological changes may contribute to the altered lymphocyte status observed in DM. However, leukocyte functions that are not directly related to immune response have seldom been studied in diabetic patients $[7,35]$.

It was shown that in mononuclear cells from patients with type 1 diabetes, 2-deoxyglucose uptake increased in response to insulin in vitro in comparison with nondiabetic subjects. This was observed only in the monocyte population [7]. Monocytes have the capacity to specifically bind insulin. This was not shown in the case of lymphocytes, but both types of cells have insulin-degrading activity [35]. Diabetes also causes important changes in lymphocyte metabolism [30]. In lymphocytes of patients with type 2 diabetes, the activity of pyruvate dehydrogenase is lower in comparison with healthy subjects $[6,28]$.

It is still not known how deoxy-D-glucose transport is altered in lymphocytes from patients with type 2 diabetes and what transporters are actually present in the lymphocyte membranes. Some contradictory data on glucose transport in lymphocytes and the importance of these cells in the pathological conditions associated with $\mathrm{DM}$ were the major reasons to focus on lymphocytes in our study. Glucose transport defects in diabetes could be conveniently studied in human subjects using blood cell types such as lymphocytes. The aim of this study was an evaluation of deoxy-D-glucose transport into lymphocytes in healthy subjects and in patients with type 2 diabetes. As a second part of the study it was planned to investigate whether the major GLUT isoforms (GLUT1, GLUT3) are involved in the transport of glucose across the lymphocyte plasma membrane.

\section{MATERIALS AND METHODS}

\section{Patients}

The study group included 60 patients with type 2 diabetes and 30 age-, weight-, and sex-matched healthy subjects serving as a control group. The clinical diagnosis of type 2 diabetes was made according to World Health Organization criteria, and all such consenting patients were enrolled, excluding those with any diabetic complications. None of the patients or healthy subjects had impaired renal function (serum creatinine concentrations $>130 \mu \mathrm{mol} / \mathrm{l}$ and no microalbuminuria), hypertension (sitting office blood pressure of more than $140 / 90 \mathrm{mmHg}$ on two occasions), hypercholesterolemia (total cholesterol $>5.0 \mathrm{mmol} / \mathrm{l}$ ), proliferative retinopathy, or impaired liver function. The diabetic patients were classified into two subgroups according to the mode of therapy. Thirty patients were treated with diet only and 30 patients were treated with diet and insulin (mean daily dose: 46.0 \pm 5.0 IU). As the control group, 30 healthy subjects with no family history of type 2 diabetes were enrolled. None of the healthy subjects had been treated with any drugs during the investigation and three months before. All the patients and healthy subjects were informed about the aim of the study and agreed to comply with all study requirements by giving their written informed consent. The investigations were carried out in accordance with the principles of the Declaration of Helsinki. The institutional review board of Warsaw Medical University approved the protocol.

\section{Lymphocyte isolation}

An overnight-fasted blood sample $(5 \mathrm{ml})$ was drawn from the antecubital vein and collected into a heparinized tube. Lymphocytes were isolated within 2 $\mathrm{h}$ from venipuncture by density gradient centrifugation in Gradisol L (Aqua-Medica, Poland; $1200 \times \mathrm{g}, 20 \mathrm{~min}$ ). Afterwards the lymphocytes were collected and washed twice with $0.9 \% \mathrm{NaCl}$ solution $(500 \times \mathrm{g}, 10 \mathrm{~min})$. After isolation, the lymphocytes were washed twice in the transport solution $(20 \mathrm{mM}$ Hepes, $150 \mathrm{mM} \mathrm{NaCI}, 5 \mathrm{mM}$ KCI, $5 \mathrm{mM} \mathrm{MgSO}$, $1.2 \mathrm{mM} \mathrm{KH}_{2} \mathrm{PO}_{4}, 2.5 \mathrm{mM} \mathrm{CaCl}_{2}, 2$ $\mathrm{mM}$ pyruvate, $\mathrm{pH}$ 7.4) [6] and an adequate volume of transport solution was added to obtain a density of $10^{6}$ cells/ml. Such a suspension was used for the investigation. 
Viability test

Lymphocyte viability was determined using vital dye exclusion. Cells were incubated in transport solution with deoxy-D-glucose. After $60 \mathrm{~min}$, a $1 \%$ solution of trypan blue $(1: 1 \mathrm{vol})$ was added to the cell suspension and living lymphocytes were counted under a light microscope.

\section{Immunocytochemistry}

This test was carried out according to a modified method described by Maher et al. [24] to reveal the presence of GLUT proteins. Commercial antibodies obtained from Chemicon International Inc. (CA, USA), were used. The primary antibodies were polyclonal rabbit anti-GLUT1 antibodies against the C-terminus of rat GLUT1 and anti-GLUT3 antibody against the C-terminus of mouse GLUT3. Horseradish peroxidase-conjugated anti-rabbit IgG was used as a secondary antibody.

Slides with lymphocytes were incubated with $3 \%$ hydrogen peroxide for $5 \mathrm{~min}$ at room temperature to inhibit endogenous peroxidase. Then the cells were washed with phosphate buffered saline (PBS) and blocked with $1 \%$ bovine serum albumin (BSA) diluted in PBS. Fixed lymphocytes were treated with rabbit antiGLUT (1:200) for 30 min at room temperature, washed three times with $1 \% \mathrm{BSA}$, and incubated with secondary antibody (1:2000) for $30 \mathrm{~min}$ at room temperature. Antibody-antigen complexes were visualized by 3,3-diaminobenzidine (DAB; Sigma, USA) according to the instructions of manufacturer. After this procedure, the slides were washed with distilled water, dehydrated through a series of graded ethanol solutions, xylene followed by the addition of D.P.X (neutral mounting medium; Aldrich, USA). For a negative control, the cells were incubated without primary antibodies for $30 \mathrm{~min}$ at room temperature.

\section{Western blot analysis}

Western blot analysis was carried out to confirm the results of immunocytochemistry. For protein expression of GLUT1 and GLUT3, an aliquot $(60 \mu \mathrm{g})$ of cell extract was re-suspended in Laemli buffer with $\beta$-mercaptoethanol and heated $\left(90^{\circ} \mathrm{C}\right)$ for 5 min. Proteins were separated by SDS-PAGE, transferred to nitrocellulose membranes, and blocked by $5 \%$ milk in TBS (20 $\mathrm{mM}$ trisma, $500 \mathrm{mM} \mathrm{NaCl}, \mathrm{pH}=7.6$ ) for $12 \mathrm{~h}$ at $4^{\circ} \mathrm{C}$. The membranes were incubated with the primary antiGLUT1 and anti-GLUT3 rabbit polyclonal antibodies (Chemicon, USA). Then the membranes were washed and incubated with secondary horseradish-conjugated goat anti-rabbit IgG antibody (Chemicon, USA). Following incubation with the secondary antibody, the membranes were washed and antibody-antigen complexes were visualized by DAB (Sigma, USA) according to the instructions of the manufacturer.
Deoxy-D-glucose uptake by lymphocytes

The experiment was carried out according to a partly modified method described by Kaliman et al. [19]. To $290 \mu \mathrm{l}\left(3 \times 10^{5}\right.$ cells $)$ of cell suspension the $1.5 \mu \mathrm{l}$ of deoxy-D-glucose, 2-[3 $\left.{ }^{3} \mathrm{H}(\mathrm{G})\right](7.70000 \mathrm{Cii} / \mathrm{mmol})$ and 7.5 $\mu \mathrm{l}$ of PBS were added. In line with results obtained earlier [34], the times of lymphocyte incubation with deoxy-D-glucose were established as 15,30 , or $60 \mathrm{~min}$. At these time points, the transport was stopped by addition of 2 vol of ice-cold $50 \mathrm{mM}$ glucose in PBS. Then deoxy-D-glucose was washed away using the same solution and the cells were lysed with $0.1 \mathrm{M} \mathrm{NaOH} / 0.1 \%$ SDS. After lysis of the cells (within $24 \mathrm{~h}$ ), the radioactivity in curie count per minute (ccpm) was determined by a scintillation counter. Each condition was run in triplicate. Non-specific uptake $(t=0)$ was determined by incubating the lymphocytes with radiolabeled glucose in the stop solution (50 mM glucose in PBS) instead of transport solution.

\section{The statistical analysis}

The results were compared using the Wilcoxon test [1] at confidence levels of 99 and $95 \%(p=0.01$ and $\mathrm{p}=0.05)$. Results were expressed as mean \pm SD.

\section{RESULTS}

The clinical characteristics of the control and diabetic subjects are summarized in Table 1.

\section{Viability test}

The procedures applied did not have any influence on the survival rate of lymphocytes (as assessed by the trypan blue vital test). There were no differences in the numbers of dead cells in the lymphocyte populations from healthy subjects and from both diabetic patients groups, and total cell viability was approximately $95 \%$.

Table 1. Subjects' characteristics (mean (SD))

\begin{tabular}{|c|c|c|c|}
\hline & \multirow{2}{*}{$\begin{array}{l}\text { Control } \\
\text { group }\end{array}$} & \multicolumn{2}{|c|}{ Diabetic patients } \\
\hline & & diet & insulin \\
\hline Number & 30 & 30 & 30 \\
\hline $\operatorname{Sex}(M / F)$ & $15 / 15$ & $15 / 15$ & $15 / 15$ \\
\hline Age (years) & $63.8(2.6)$ & $63.9(3.1)$ & $65.2(2.5)$ \\
\hline BMI $\left(\mathrm{kg} / \mathrm{m}^{2}\right)$ & $24.1(1.0)$ & $24.5(1.6)$ & $25.0(1.1)$ \\
\hline $\begin{array}{l}\text { Duration of diabetes } \\
\text { (years) }\end{array}$ & 0 & $2.5(1.0)$ & $7.3(2.7)$ \\
\hline Insulin dose ( IU/24 h) & 0 & 0 & $46.0(5.0)$ \\
\hline $\begin{array}{l}\text { Fasting glycemia } \\
(\mathrm{mmol} / \mathrm{l})\end{array}$ & $4.9(0.3)$ & $6.0(0.7)$ & $6.3(0.6)$ \\
\hline $\mathrm{HbA}_{1 \mathrm{C}}(\%)$ & $4.9(0.6)$ & $6.6(0.7)$ & $7.0(0.5)$ \\
\hline $\begin{array}{l}\text { Total cholesterol } \\
(\mathrm{mmol} / \mathrm{l})\end{array}$ & $4.2(0.5)$ & $5.2(0.6)$ & $5.1(0.4)$ \\
\hline Triglycerides (mmol/l) & $1.4(0.2)$ & $1.8(0.3)$ & $1.7(0.3)$ \\
\hline
\end{tabular}




\section{Immunocytochemistry}

Immunocytochemistry showed the presence of the specific transport proteins GLUT1 and GLUT3 in the investigated lymphocytes. In the control sample (without the first antibody), the reaction was negative. Immunocytochemical reactions with antibodies against GLUT1 and GLUT3 were positive in lymphocytes in both groups of diabetic patients and in the control group (Fig. 1-3). Staining was more intensive for GLUT3 than for GLUT1 in all the groups under study. The intensities of the reactions for GLUT1 and GLUT3 were similar in all the investigated groups.

\section{Western blot analysis}

The results of Western blot analysis revealed two bands, characteristic of GLUT1 (49 kDa) and of GLUT3 (45 kDa). The band characteristic of GLUT3 was stronger than the band of GLUT1 (Fig. 4).

\section{Deoxy-D-glucose uptake by lymphocytes}

Deoxy-D-glucose uptake values are presented as ccpm. In order to evaluate the kinetics of the process, the results at 30 and $60 \mathrm{~min}$ are presented as a multiples of the respective 15-min value. During the experiment, a gradual increase in deoxy-D-glucose uptake was observed in healthy subjects. Mean ccpm values in this group at 15, 30, and 60 min were 5110, 10660.63, and 19667.73, respectively. These values present an almost linear dynamics of deoxy-D-glucose uptake. At $30 \mathrm{~min}$ the ccpm value increased 2.09-fold and at $60 \mathrm{~min} 3.85$ -fold in comparison with the 15-min value.

In diabetic patients, deoxy-D-glucose uptake also increased over time, but the values and dynamics of the process were different from those observed in the healthy population. In the diet-treated diabetic group, the deoxy-D-glucose uptake value at 15 min was 7026.03 ccpm. At 30 min the value was $7176.80 \mathrm{ccpm}$, increasing only 1.02-fold. At $60 \mathrm{~min}$, deoxy-D-glucose uptake reached 10886.77 ccpm, a value 1.55 -fold greater than at $15 \mathrm{~min}$. There was a statistically significant difference in results between the diet-treated group vs. the control group (Fig. 5).

In the insulin-treated diabetic group, glucose transport presented different characteristics. Values of deoxy-D-glucose uptake were very high. At $15 \mathrm{~min}$ it was $10748.23 \mathrm{ccpm}$, at $30 \mathrm{~min} 23150.77 \mathrm{ccpm}$, and at 60 min 25141.13 ccpm. When compared with the $15-\mathrm{min}$ value, the values increased 2.15 -fold at $30 \mathrm{~min}$ and only 2.34 -fold at $60 \mathrm{~min}$. There was a statistically significant difference in the results between the insulin-treated group vs. the control group (Fig. 6).

\section{DISCUSSION}

Diabetic patients cannot be regarded as a homogenous population when considering lymphocyte function.
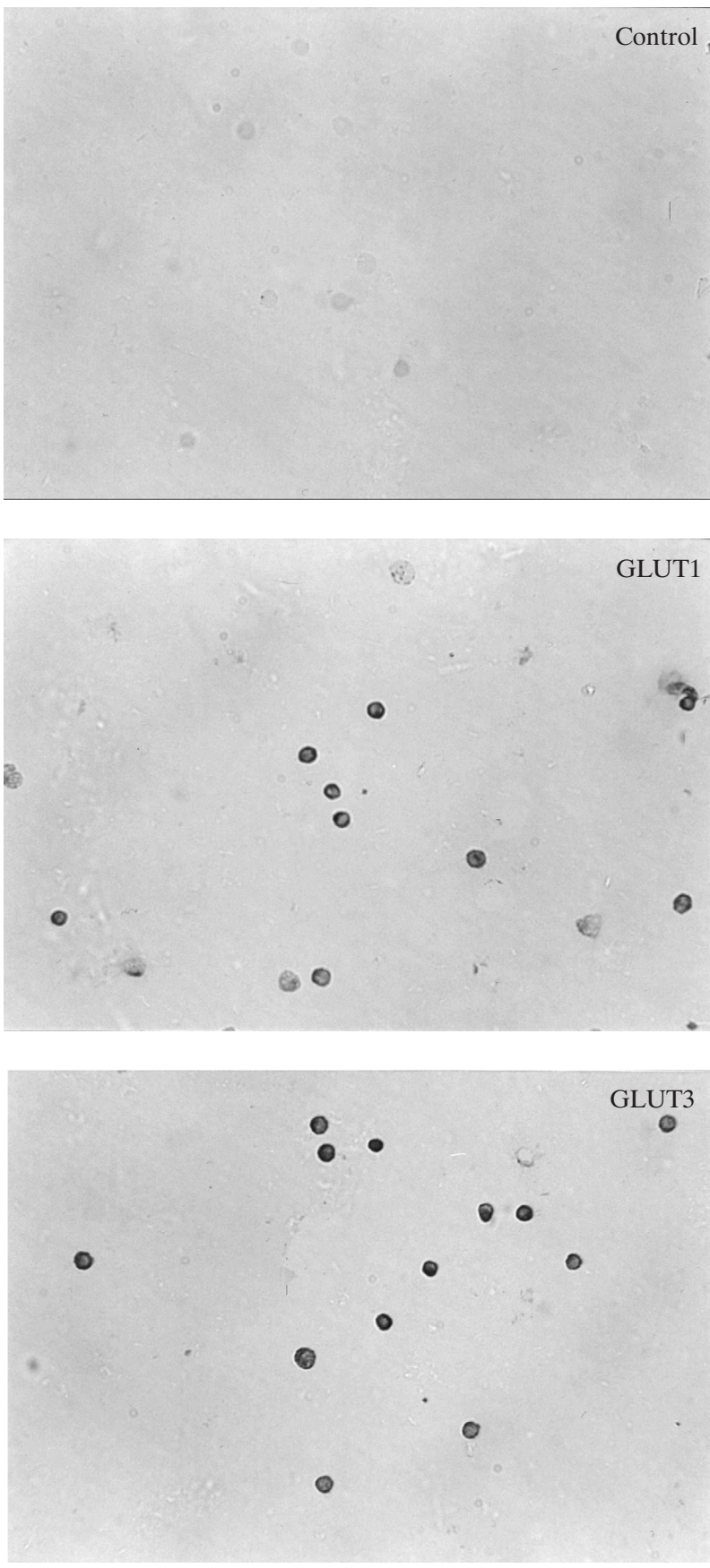

Fig. 1. Immunocytochemical detection of GLUT1 and GLUT3 proteins in lymphocytes from healthy subjects.

Glucose transport into lymphocytes in both of the diabetic subject groups studied, has its distinct characteristics. Patients treated with diet represent a population in the early phase of the disease. It can be expected that cellular glucose transport at this stage of diabetes is not significantly changed. Some studies show that in type 1 diabetes, 2-deoxy-D-glucose uptake does not correlate with duration of the disease [7]. These findings cannot be applied to type 2 diabetes directly, but give an idea of alterations in the process of glucose transport in patients with pathological glucose metabolism. 

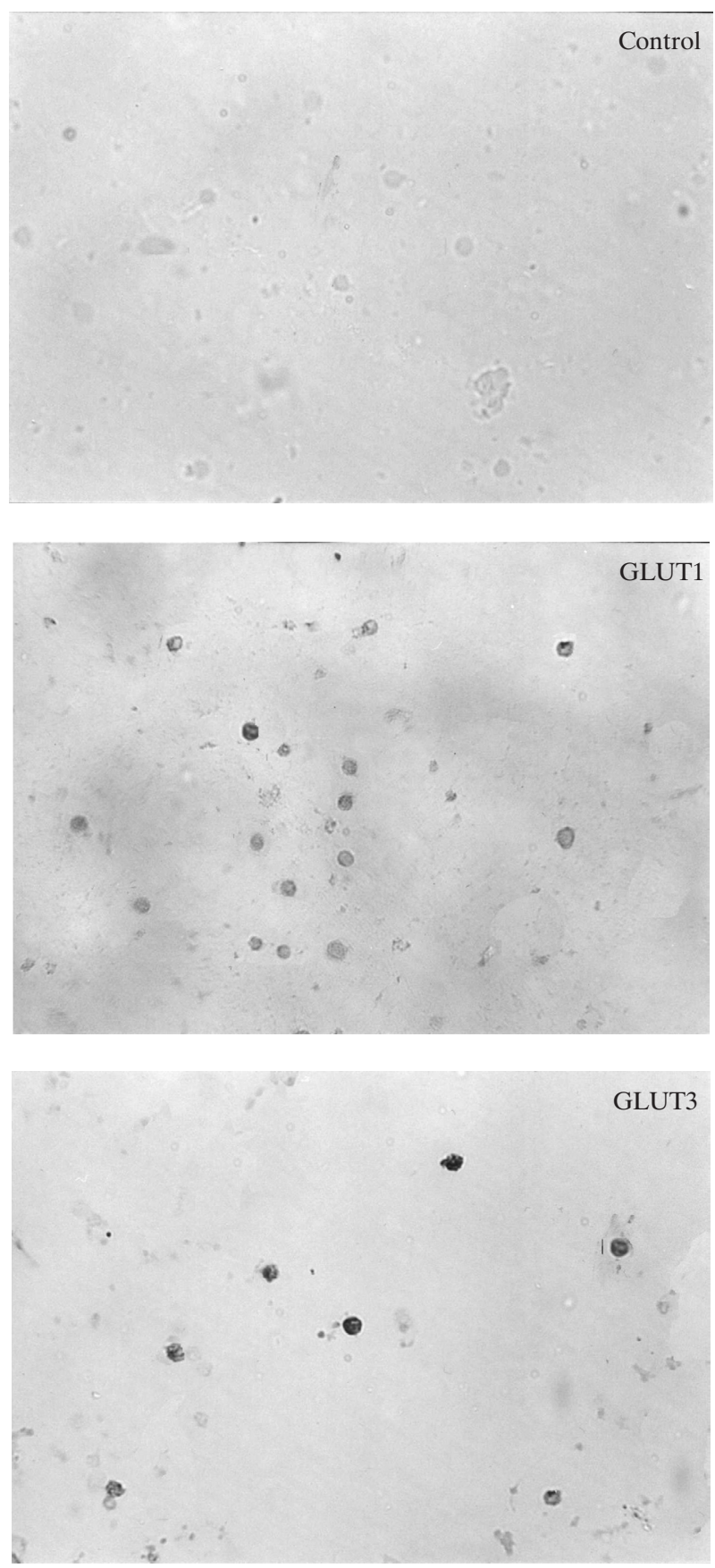

Fig. 2. Immunocytochemical detection of GLUT1 and GLUT3 proteins in lymphocytes from diet treated diabetic patients.

In our study, the deoxy-D-glucose transport into lymphocytes of diet-treated patients was altered. In the diet-treated group at $15 \mathrm{~min}$, the values of deoxy-D-glucose uptake were higher than in the control group, which is a feature characteristic of all diabetic patients. Surprisingly, at 30 and 60 min of observation, the uptake values in the diet-treated group were lower, increasing slowly with time. This indicates that glucose transport in this group is delayed in time, which is an important alteration occurring early in diabetes. The insulin-treated group represents a population of diabetic patients at
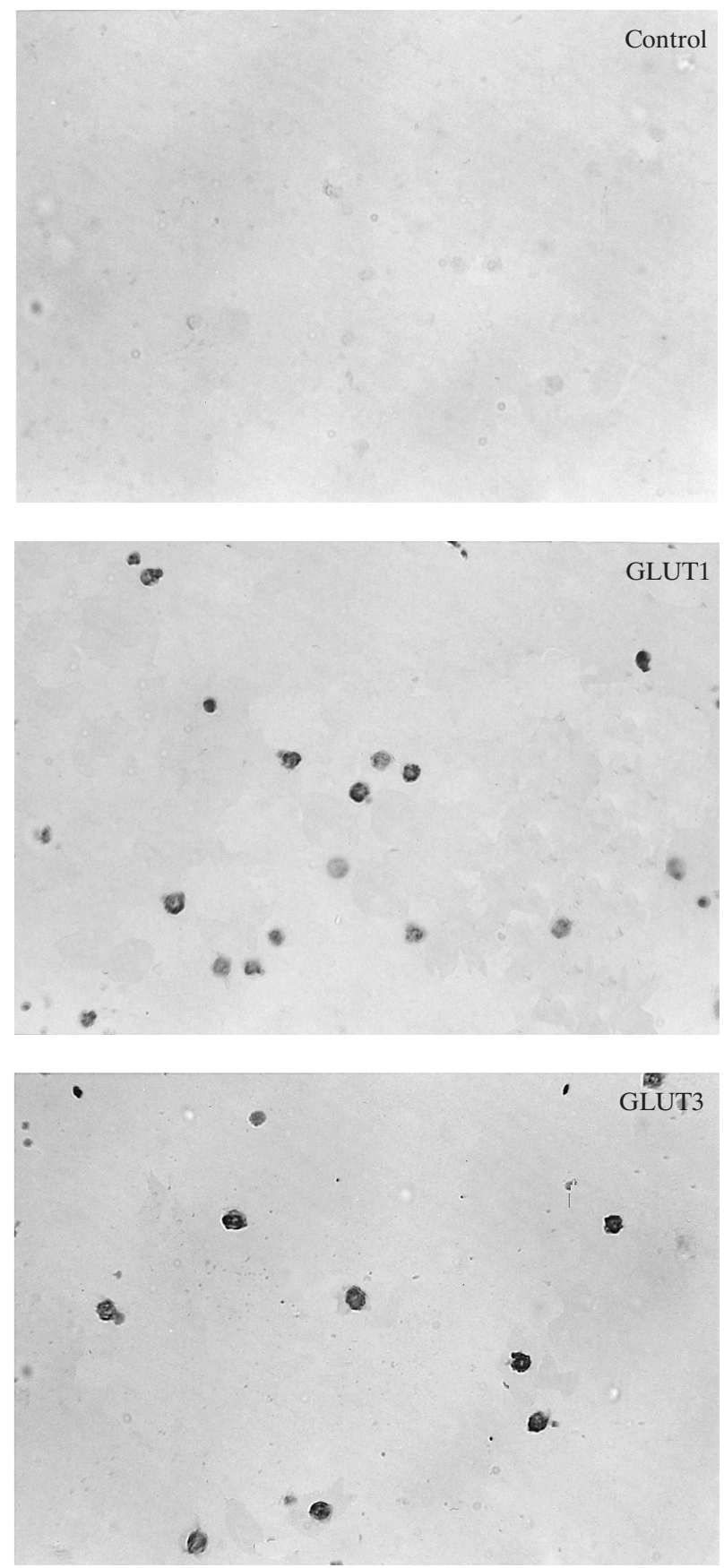

Fig. 3. Immunocytochemical detection of GLUT1 and GLUT3 proteins in lymphocytes from insulin treated diabetic patients.

a more advanced stage of the disease. Very high values of deoxy-D-glucose uptake were observed at all times, but especially at the beginning of the experiment. At 15 min the ccpm value was more than 2-fold the value noted in the control group and more than the value in the diet-treated group (Fig. 7). These differences were still present at 30 and $60 \mathrm{~min}$ of observation. The values at $30 \mathrm{~min}$ had increase 2-fold, i.e. similar to the situation in the control group but at a much higher level. Later there is a drop in glucose uptake, and at $60 \mathrm{~min}$ a plateau phase was observed. 


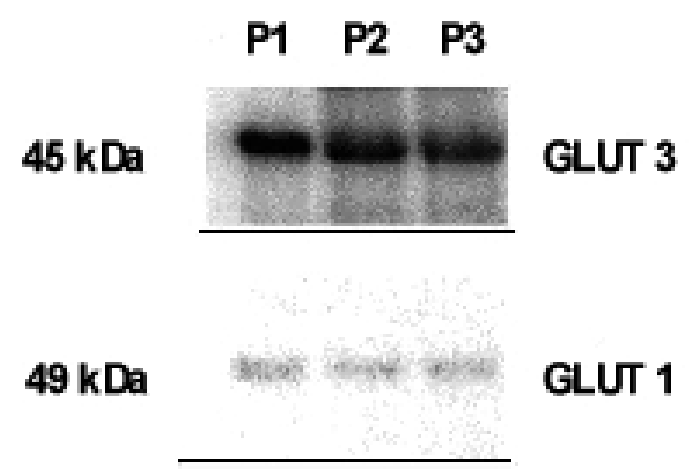

Fig. 4. Western blot analysis of representative samples: P1 - healthy subject, P2 - diet treated diabetic patient, P3 - insulin treated diabetic patient. The results of Western blot analysis revealed two bands, characteristic of GLUT1 (49 kDa) and of GLUT3 (45 kDa).

The differences between the diabetic patient groups may depend on the mode of therapy and also result from the metabolic changes developing during the progression of diabetes. In the case of patients treated with diet, it is possible that these differences are caused by the disease only. There are other factors, such as diet content [22] and physical activity, that influence glucose metabolism in the course of chronic conditions. It has been shown that exercise stimulates both glucose uptake and glycogen synthesis. These investigations were carried out in human muscles [8, 14], with the focus on GLUT proteins. Lymphocyte studies concerning the influence of exercise on glucose transport in humans are not reported. However, in rats, a stimulation of GLUT1 expression in splenic lymphocytes has been observed after exercise [3]. In patients treated with insulin, alterations in glucose transport may result from both the disease itself and the mode of therapy. Insulin is the most potent medication that influences glucose metabolism. Glucose transport into cells increases in the presence of insulin. In cultured 3T3-L1 adipocytes, insulin rapidly stimulates glucose movement into cells. The observed transport rate was over 10 -fold higher than in the control group. The investigations revealed that GLUT1 has an important part in this process [3].

Results published by other authors [7, 11] on the influence of insulin on deoxy-D-glucose uptake by lymphocytes differ from the outcomes of our study. Those authors reported that insulin stimulated glucose uptake only in monocytes, whereas it did not have any influence on lymphocytes. These studies involved patients with type 1 diabetes, who in many aspects differ from type 2 diabetic patients. Autoimmune reactions that are believed to play a major role in the pathogenesis of type 1 diabetes may have a great impact on lymphocyte functions. Moreover, type 1 diabetic patients develop vascular complications earlier and more frequently. We excluded patients from our study with vascular complications of diabetes, who are certainly a population at the most advanced stage of the disease. In our research, we investigated the transport of glucose in patients treated with insulin, but did not add insulin to the isolated lymphocyte samples. In contrast, other investigators added insulin to already isolated blood cells.

The immunocytochemical method and Western blot analysis showed the presence of glucotransporters GLUT1 and GLUT3 in the investigated lymphocytes. These proteins have been considered major glucotrans-
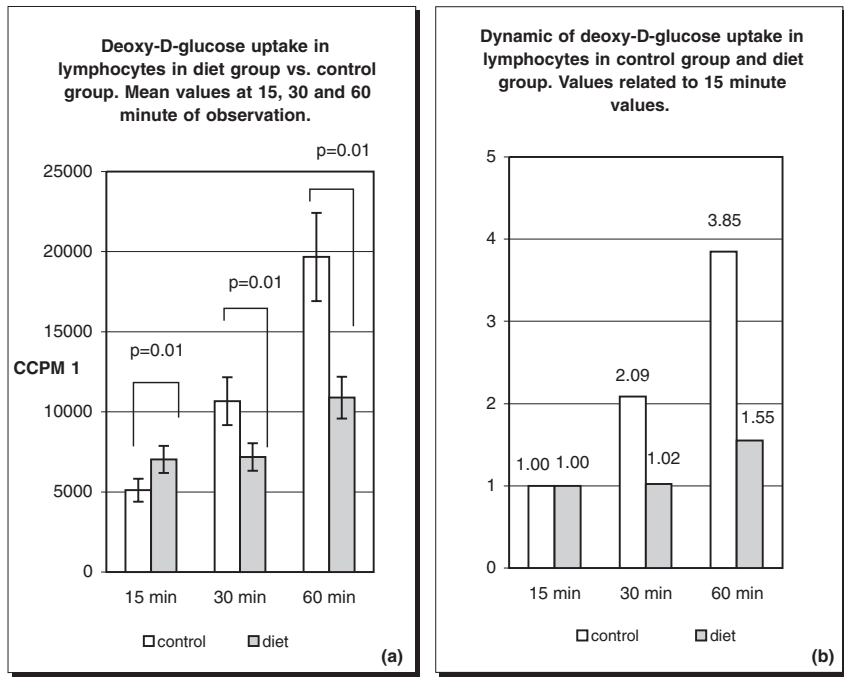

Fig. 5. Deoxy-D-glucose uptake (a) and its dynamics (b) in lymphocytes of healthy subjects and diet treated patients. Differences in deoxy-D-glucose uptake between diet treated patients and control group were statistically significant $(\mathrm{p}=0.01)$ at 15,30 and 60 min of the observation (a). Increase in deoxy-D-glucose uptake is gradual in healthy subjects with almost linear dynamic (b). In diet treated patients increase in transport rate is delayed.
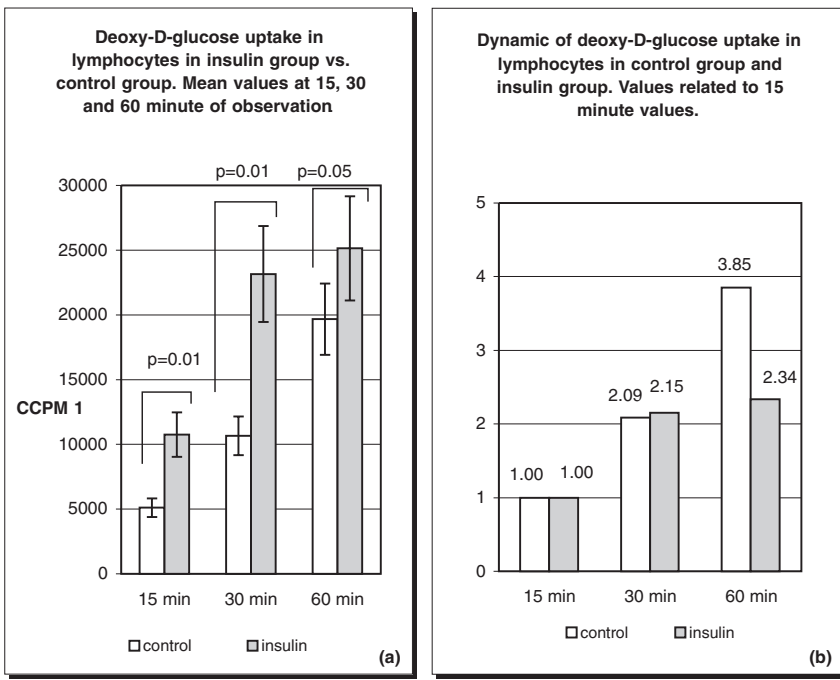

Fig. 6. Deoxy-D-glucose uptake (a) and its dynamics (b) in lymphocytes of healthy subjects and insulin treated patients. Differences in deoxy-D-glucose uptake between insulin treated patients and control group were statistically significant at 15,30 $(\mathrm{p}=0.01)$ and $60(\mathrm{p}=0.05)$ minutes of the observation $(\mathbf{a})$. Slowdown of deoxy-D-glucose uptake at $60 \mathrm{~min}$ is characteristic of insulin treated patients (b). 


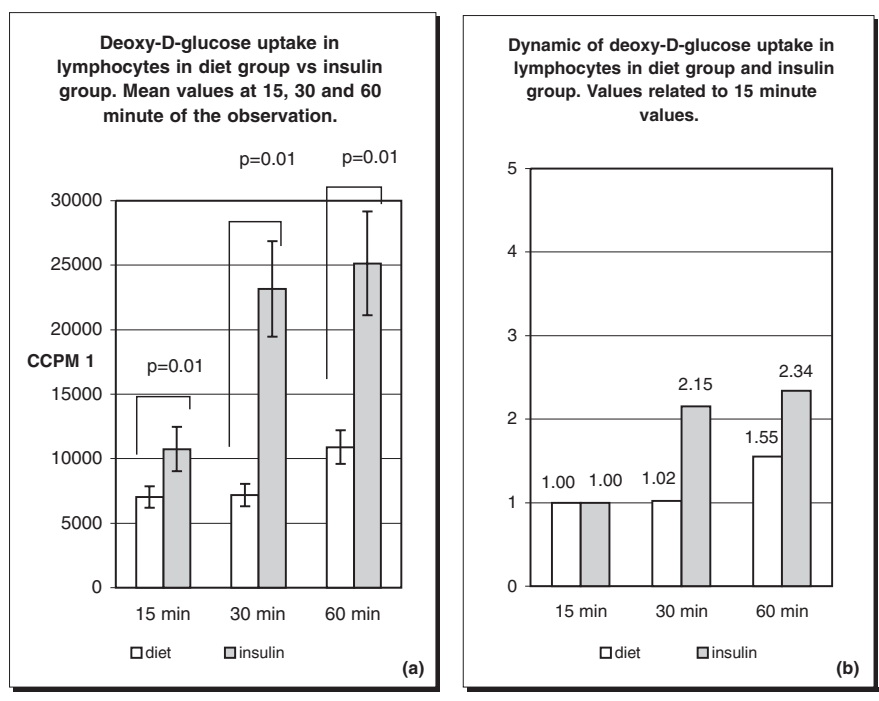

Fig. 7. Deoxy-D-glucose uptake (a) and its dynamics (b) in lymphocytes of diet treated patients and insulin treated patients. Differences in deoxy-D-glucose uptake between diet treated patients and insulin treated patients were statistically significant $(p=0.01)$ at 15,30 and 60 min of the observation with greatest difference at $30 \mathrm{~min}$ (a). Dynamic of deoxy-D-glucose uptake differs between two diabetic patients group (b).

porters in these blood cells. We found a very strong effect of insulin on deoxy-D-glucose uptake in peripheral blood lymphocytes. Although we have not found the existence of other glucotransporters in human peripheral blood lymphocytes in available literature, these results suggest the expression of an insulin-sensitive glucose transporter in these cells. These findings are consistent with published data on GLUT expression in the leukocytes of healthy subjects, but not in lymphocytes where GLUT proteins were found only in small amounts [21]. It was also shown that monocytes expressed GLUT1 protein in type 1 diabetes [7]. Information regarding GLUT expression in leukocytes in type 2 diabetic patients is scarce.

In conclusion, the results of our study show that glucose transport in lymphocytes is profoundly altered in type 2 diabetes. There are statistically significant differences in glucose uptake between each of the diabetic patients groups in comparison with healthy subjects. This phenomenon could reflect the adaptation of immunocompetent cells to the abnormal metabolic conditions (hyperglycemia, etc.) typical of diabetes. There was also a significant difference between the groups of patients treated with different modes of therapy. Treatment, however, does not normalize altered lymphocyte glucose transport function. Insulin therapy stimulates glucose uptake, but it is difficult to determine if this is advantageous for lymphocyte functions. High glucose concentrations in cytoplasm may be toxic as well. The investigated groups represent patients at different stages of the disease: patients at an early stage who require diet only in order to maintain glycemia within the accepted range and patients at advanced stage who require insulin. Glucose transport properties distinctly change with the progression of diabetes.

Peripheral blood lymphocytes are particularly vulnerable to alterations in blood glucose levels. The major glucotransporters are expressed on these cells. Blood cells such as lymphocytes are much more easily available for studies in humans than muscle or adipose tissue. Lymphocytes are easily obtainable and retain viability during in vitro culturing (in contrast to granulocytes, which are fragile, and monocytes, which are scarce and difficult to isolate). Therefore, these cells may become a convenient model for studies of the influence of diabetes on glucose utilization in human subjects. In conclusion, we postulate that peripheral blood lymphocytes should be considered as a promising tool in the field of glucose transport investigations.

Acknowledgment: We are indebted to Maria Nowaczyk, Ph.D., Department of Clinical Immunology, Medical University of Warsaw, for valuable support in the methodology of lymphocyte isolation.

\section{REFERENCES}

1. Armitage P. (1971): Statistical methods in medical research. 3rd Edition. Blackwell Scientific Publications, Oxford.

2. Balon T. W. and Nadler J. L. (1997): Evidence that nitric oxide increases glucose transport in skeletal muscle. J. Appl. Physiol., 82, 359-363.

3. Calderhead D. M., Kitagawa K., Tanner L. I., Holman G. D. and Lienhard G. E. (1990): Insulin regulation of two glucose transporters in 3T3-L1 adipocytes. J. Biol. Chem., 265, 13801-13808.

4. Carayannopoulos M. O., Chi M. M., Cui Y., Pingsterhaus J. M., McKnight R. A., Mueckler M., Davaskar S. U. and Moley K. H. (2000): GLUT8 is a glucose transporter responsible for insulin-stimulated glucose uptake in the blastocyst. Proc. Natl. Acad. Sci. USA, 97, 7313-7318.

5. Cheta D., Cheta N., Mihalache N., Micu D., Ionescu-Tirgoviste C., Mihailescu E. and Mincu I. (1982): Study of some lymphocyte metabolic parameters in diabetes mellitus. Med. Interne, 20, 25-32.

6. Curto M., Piccinini M., Rabbone I., Mioletti S., Mostert M. Bruno R. and Rinoudo M. T. (1997): G proteins and regulation of pyruvate dehydrogenase activity by insulin in human circulating lymphocytes. Int. J. Biochem. Cell. Biol., 29, 1207-1217.

7. Daneman D., Zinman B., Elliott M. E., Bilan P. J. and Klip A. (1992): Insulin-stimulated glucose transport in circulating mononuclear cells from nondiabetic and IDDM subjects. Diabetes, 41, 227-234.

8. Daugaard J. R., Nielsen J. N., Kristiansen S., Andersen J. L., Hargreaves M. and Richter E. A. (2000): Fiber type-specific expression of GLUT4 in human skeletal muscle: influence of exercise training. Diabetes, 49, 1092-1095.

9. Delamaire M., Maugendre D., Moreno M., Le Goff M. C., Allannic H. and Genetet B. (1997): Impaired leucocyte functions in diabetic patients. Diabet. Med., 14, 29-34.

10. Doege H., Schurmann A., Bahrenberg G., Brauers A. and Joost H. G. (2000): GLUT8, a novel member of the sugar transport facilitator family with glucose transport activity. J. Biol. Chem., 275, 16275-16280.

11. Estrada D. E., Elliott E., Zinman B.., Poon I., Liu Z., Klip A. and Daneman D. (1994): Regulation of glucose trans- 
port and expression of GLUT3 transporters in human circulating mononuclear cells: studies in cells from insulin-dependent diabetic and nondiabetic individuals. Metabolism, 43, 591-598.

12. Gallacher S. J., Thomson G., Fraser W. D., Fisher B. M., Gemmell C. G. and MacCuish A. C. (1995): Neutrophil bactericidal function in diabetes mellitus: evidence for association with blood glucose control. Diabet. Med., 12, 916-920.

13. Hayashi T., Wojtaszewski J. F. and Goodyear L. J. (1997): Exercise regulation of glucose transport in skeletal muscle. Am. J. Physiol., 273 (6 Pt 1), E1039-E1051.

14. Ivy J. L. and Kuo C.-H. (1998): Regulation of GLUT4 protein and glycogen synthase during muscle glycogen synthesis after exercise. Acta Physiol. Scand., 162, 295-304.

15. Johnson J. H., Crider B. P., McCorkle K., Alford M. and Unger R. H. (1990): Inhibition of glucose transport into rat islet cells by immunoglobulins from patients with newonset insulin-dependent diabetes mellitus. N. Engl. J. Med., 322, 653-659.

16. Johnson J. H., Ogawa A., Chen L., Orci L., Newgard C. B., Alam T. and Unger R. H. (1990): Underexpression of beta cell high $\mathrm{Km}$ glucose transporters in noninsulin-dependent diabetes. Science, 250, 546-549.

17. Joost H. G. and Thorens B. (2001): The extended GLUT family of sugar/polyol transport facilitators: nomenclature, sequence characteristics and potential function of its novel members. Mol. Membr. Biol., 18, 247-256.

18. Joshi N., Caputo G. M., Weitekamp M. R. and Karchmer A. W. (1999): Infections in patients with diabetes mellitus. N. Engl. J. Med., 341, 1906-1912.

19. Kaliman P., Vinals F., Testar X., Palacin M. and Zorzano A. (1995): Disruption of GLUT1 glucose carrier trafficking in L6E9 and Sol8 myoblasts by the phosphatidylinositol 3-kinase inhibitor wortmannin. Biochem. J., 312 (Pt 2), 471-477.

20. Kelley D. E., Williams K. V. and Price J. C. (1999): Insulin regulation of glucose transport and phosphorylation in skeletal muscle assessed by PET. Am. J. Physiol., 277 (2 Pt 1), E361-E369.

21. Korgun E. T., Demir R., Sedlmayr P., Desoye G., Arikan G. M., Puerstner P., Haeusler M., Dohr G., Skofitsch G and Hahn T. (2002): Sustained hypoglycemia affects glucose transporter expression of human blood leukocytes. Blood Cells Mol. Dis., 28, 152-159.

22. Lichtenstein A. H. and Schwab U. S. (2000): Relationship of dietary fat to glucose metabolism. Atherosclerosis, 150, 227-243.

23. Longo N. and Elsas L. J. (1998): Human glucose transporters. Adv. Pediatr., 45, 293-313.

24. Maher F., Davies-Hill T. M., Lysko P. G., Henneberry R. C. and Simpson I. A. (1991): Expression of two glucose transporters, GLUT1 and GLUT3, in cultured cerebellar neurons: evidence for neuron-specific expression of GLUT3. Mol. Cell. Neuronsci., 2, 351-360.

25. McVie-Wylie A. J., Lamson D. R. and Chen Y. T. (2001): Molecular cloning of a novel member of the GLUT family of transporter, SLC2a10 (GLUT10), localized on chromosome 20q13.1: a candidate gene for NIDDM susceptibility. Genomics, 72, 113-117.

26. Moriguchi S., Kato M., Sakai K., Yamamoto S. and Shimizu E. (1998): Decreased mitogen response of splenic lymphocytes in obese Zucker rats is associated with the decreased expression of glucose transporter 1 (GLUT-1). Am. J. Clin. Nutr., 67, 1124-1129.
27. Moriguchi S., Kato M., Sakai K., Yamamoto S. and Shimizu E. (1998): Exercise training restores decreased cellular immune functions in obese Zucker rats. J. Appl. Physiol., 84, 311-317.

28. Mostert M., Rabbone I., Piccinini M., Curto M., Vai S., Musso A. and Rinaudo M. T. (1999): Derangements of pyruvate dehydrogenase in circulating lymphocytes of NIDDM patients and their healthy offspring. J. Endocrinol. Invest., 22, 519-526.

29. Otton R., Carvalho C. R., Mendonca J. R. and Curi R. (2002): Low proliferation capacity of lymphocytes from alloxan-diabetic rats: involvement of high glucose and tyrosine phosphorylation of Shc and IRS-1. Life Sci., 71, 2759-2771.

30. Otton R., Mendonca J. R. and Curi R. (2002): Diabetes causes marked changes in lymphocyte metabolism. J. Endocrinol., 174, 55-61.

31. Peters J. H. and Hausen P. (1971): Effect of phytohemagglutinin on lymphocyte membrane transport. 2. Stimulation of "facilitated diffusion" of 3-O-methylglucose. Eur. J. Biochem., 19, 509-513.

32. Phay J. E., Hussain H. B. and Moley J. F. (2000): Cloning and expression analysis of a novel member of the facilitative glucose transporter family, SLC2A9 (GLUT9). Genomics, 66, 217-220.

33. Phay J. E., Hussain H. B. and Moley J. F. (2000): Strategy for identification of novel glucose transporter family members by using internet-based genomic databases. Surgery, 128, 946-951.

34. Piatkiewicz P., Taton J. and Czech A. (2003): Impairment of glucose transport into lymphocytes influenced by Type 2 diabetes mellitus. Diabetes Metab., 29, 4S51.

35. Powers A. C., Solomon S. S. and Duckworth W. C. (1980): Insulin degradation by mononuclear cells. Diabetes, 29, 27-32.

36. Reagan L. P., Gorovits N., Hoskin E. K., Alves S. E., Katz E. B., Grillo C. A., Piroli G. G., McEwen B. S. and Charron M. J. (2001): Localization and regulation of GLUTx1 glucose transporter in the hippocampus of streptozotocin diabetic rats. Proc. Natl. Acad. Sci. USA, 98, 2820-2825.

37. Rinaudo M.T., Curto M., Rabbone I., Paccinini M., Bruno R., Mioletti S. and Gamba S. (1994): Effect of sulfonylurea agents on pyruvate dehydrogenase activity in circulating lymphocytes from patients with non-insulin-dependent diabetes mellitus (NIDDM). J. Diabetes Complications, 8, 221-225.

38. Shikhman A. R., Brinson D. C., Valbracht J. and Lotz M. K. (2001): Cytokine regulation of facilitated glucose transport in human articular chondrocytes. J. Immunol., 167, 7001-7008.

39. Thornton G. F. (1971): Infections and diabetes. Med. Clin. North Am., 55, 931-938.

40. Valerius N. H., Eff C., Hansen N. E., Karle H., Nerup J., Soeberg B. and Sorensen S. F. (1982): Neutrophil and lymphocyte function in patients with diabetes mellitus. Acta Med. Scand., 211, 463-467.

41. Wheat L. J. (1980): Infection and diabetes mellitus. Diabetes Care, 3, 187-197.

42. Wood I. S. and Trayhurn P. (2003): Glucose transporters (GLUT and SGLT): expanded families of sugar transport proteins. Br. J. Nutr., 89, 3-9.

43. Wu X. and Freeze H. H. (2002): GLUT14, a duplicon of GLUT3, is specifically expressed in testis as alternative splice forms. Genomics, 80, 553-557. 